\title{
Journal of Heart and Cardiology
}

\section{Multiple Giant Left Atrial Thrombi in Mitral Stenosis}

\section{Suma M. Victor*, Ramkumar S, Ezhilan J}

Senior consultant cardiologist, Madras medical mission, Chennai. India

*Corresponding author: Suma M. Victor, DNB., Institute of Cardiovascular Diseases, Madras Medical Mission, 4A, J.J. Nagar, Mogappair, Chennai - 600 037, India, Tel: 9144 26565961; Fax: 9144 26565859; E-mail: sumavictor@yahoomail.com

Citation: Suma M. Victor, et al. Multiple Giant Left Atrial Thrombi in Mitral Stenosis. (2017) J Heart Cardiol 3(2): 31- 32.

Received Date: November 23, 2016

Accepted Date: May 24, 2017

Published Date: May 26, 2017

\section{Abstract}

Rheumatic Heart Disease (RHD) is rarely seen in developed countries but still is a common cause of Mitral valve Stenosis (MS) in the developing world. This case demonstrates unusual echocardiographic images of multiple giant Left Atrial (LA) thrombi as a consequence of chronic severe MS.
DOI: $10.15436 / 2378-6914.17 .1226$

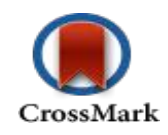

\section{Case Report}

A 55 year old lady, known to have RHD, underwent closed mitral valvotomy 15 years back, presented with palpitations and worsening dyspnoea. She had not been on any medication for past 10 years. Her ECG showed atrial fibrillation with fast ventricular rate. The chest roentgenogram demonstrated severe pulmonary hypertension with enlarged LA. Transthoracic echocardiography established a diagnosis of severe mitral restenosis $\left(0.6 \mathrm{~cm}^{2}\right)$ and revealed hugely dilated LA with multiple thrombi (Figure 1), the largest measuring $3.3 \mathrm{~cm} \times 3.9 \mathrm{~cm}$, close to the roof and septum with no obvious attachment (Figure 2). Two more thrombi are seen attached to the floor of LA and another thrombus in the appendage. Patient was stabilized with medication and underwent successful mitral valve replacement surgery with LA clot removal and LA appendage exclusion. Post operatively she had an uneventful course and asymptomatic on follow-up. ("Supplementary: movie clips")

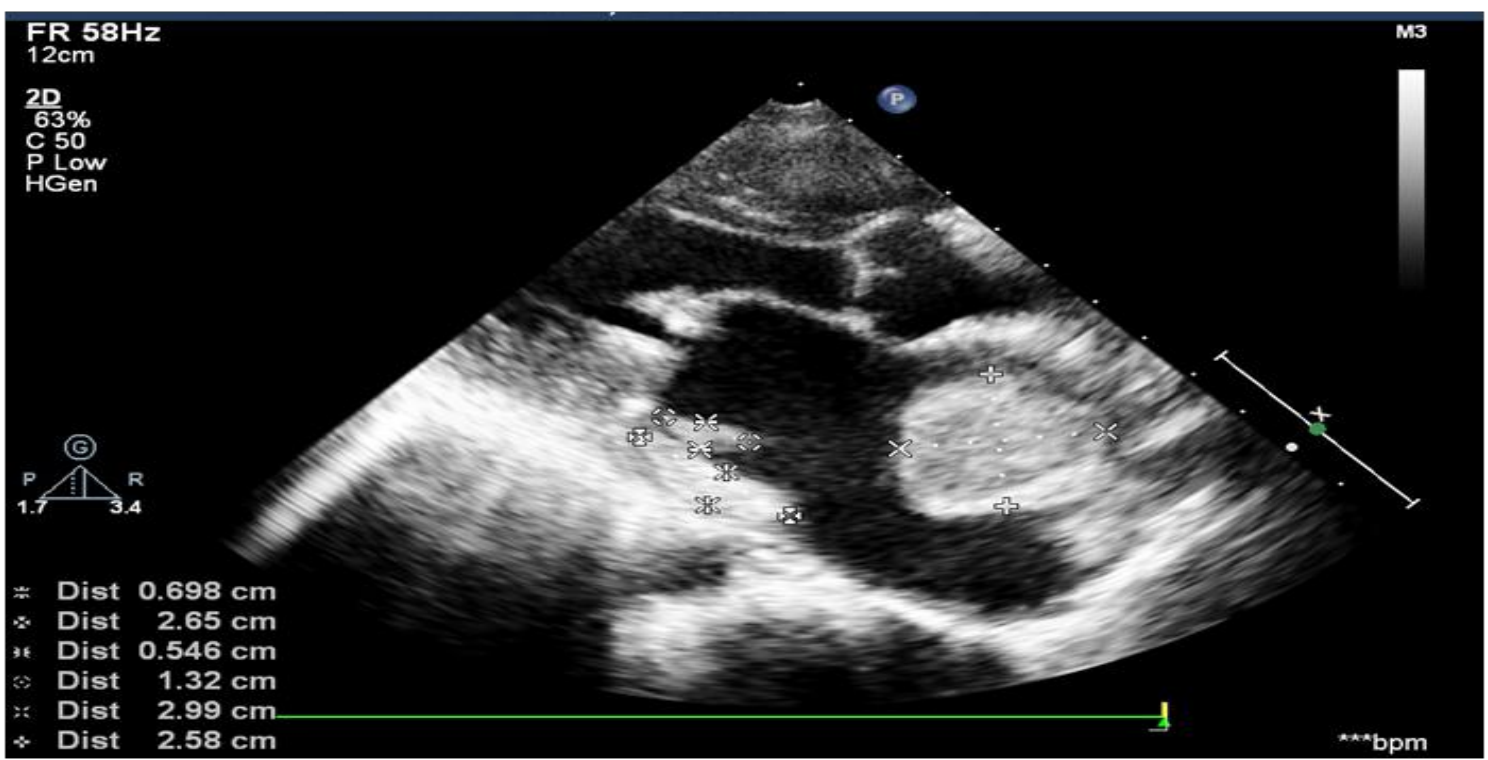

Figure 1: Hugely dilated LA with multiple thrombi.

Copy rights: () 2017 Suma M. Victor. This is an Open access article distributed under the terms of Creative Com- 


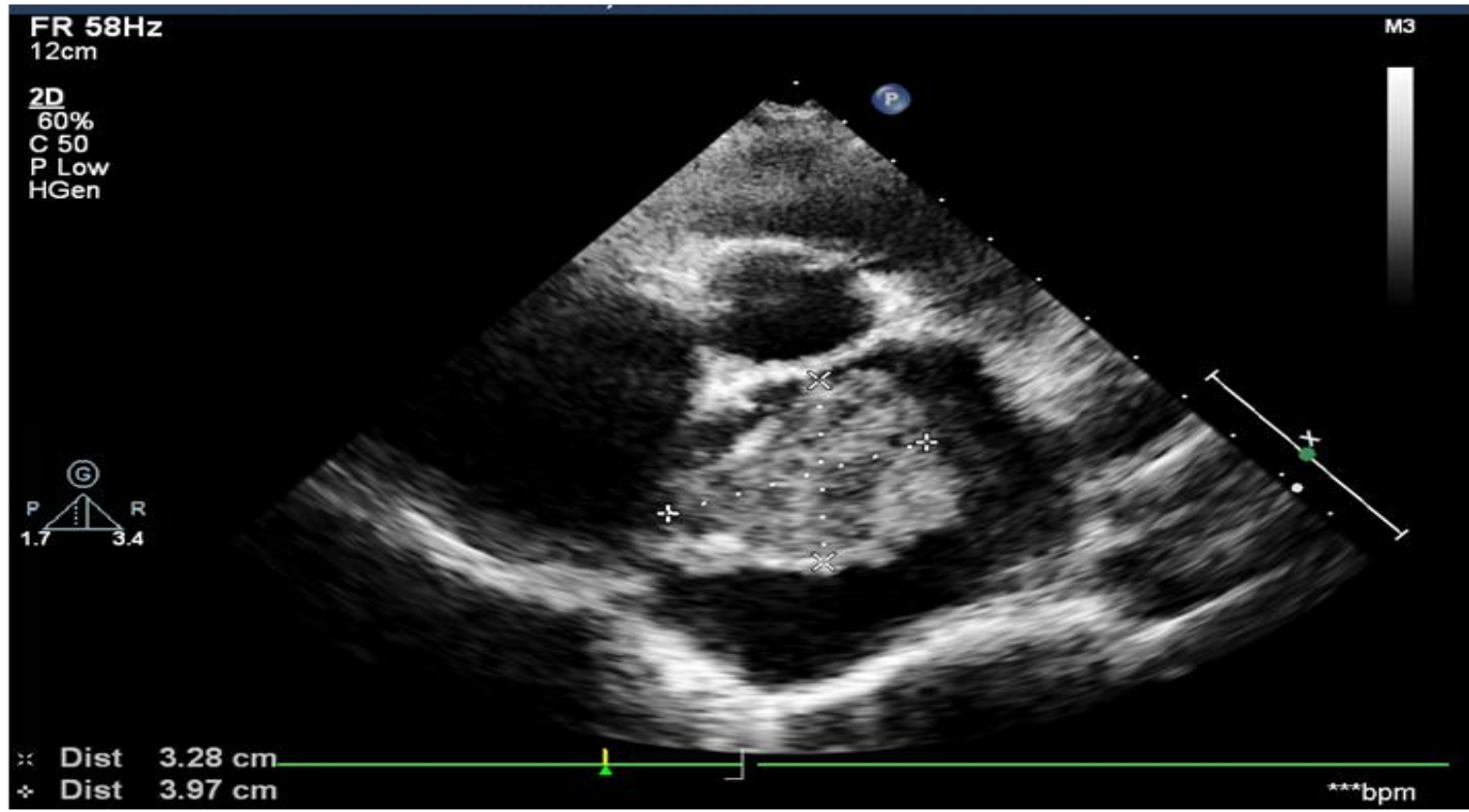

Figure 2: Giant left atrial thrombus.

\section{Discussion}

Thrombi in LA occur nearly in $17 \%$ of patients with $\mathrm{MS}^{[1]}$. Frequent risk factors for thrombus formation are atrial arrhythmias, old age, and enlarged LA and low cardiac output state ${ }^{[2]}$. The common site for finding thrombi is in the left atrial appendage ${ }^{[3]}$, based on the site of occurrence LA thrombi are classified into 7 types by Manjunath et al ${ }^{[4]}$. However, multiple thrombi are rarely seen in the present era even in developing countries. Although having multiple thrombi in LA increases the risk of stroke by manifold, our patient did not have any history of stroke even without any anticoagulation. Medical therapy in these patients include heart rate or rhythm control, anticoagulation to prevent thromboembolism, diuretics, prophylaxis against recurrent rheumatic carditis and infective endocarditis ${ }^{[5]}$. Definitive treatment includes mitral valve replacement with removal of thrombi and left atrial appendage exclusion to prevent further occurrence of thrombus formation. Prosthetic valve choice depends upon patient age, the risk of anticoagulation, and patient preference ${ }^{[6]}$.

\section{Supplementary: movie clips}

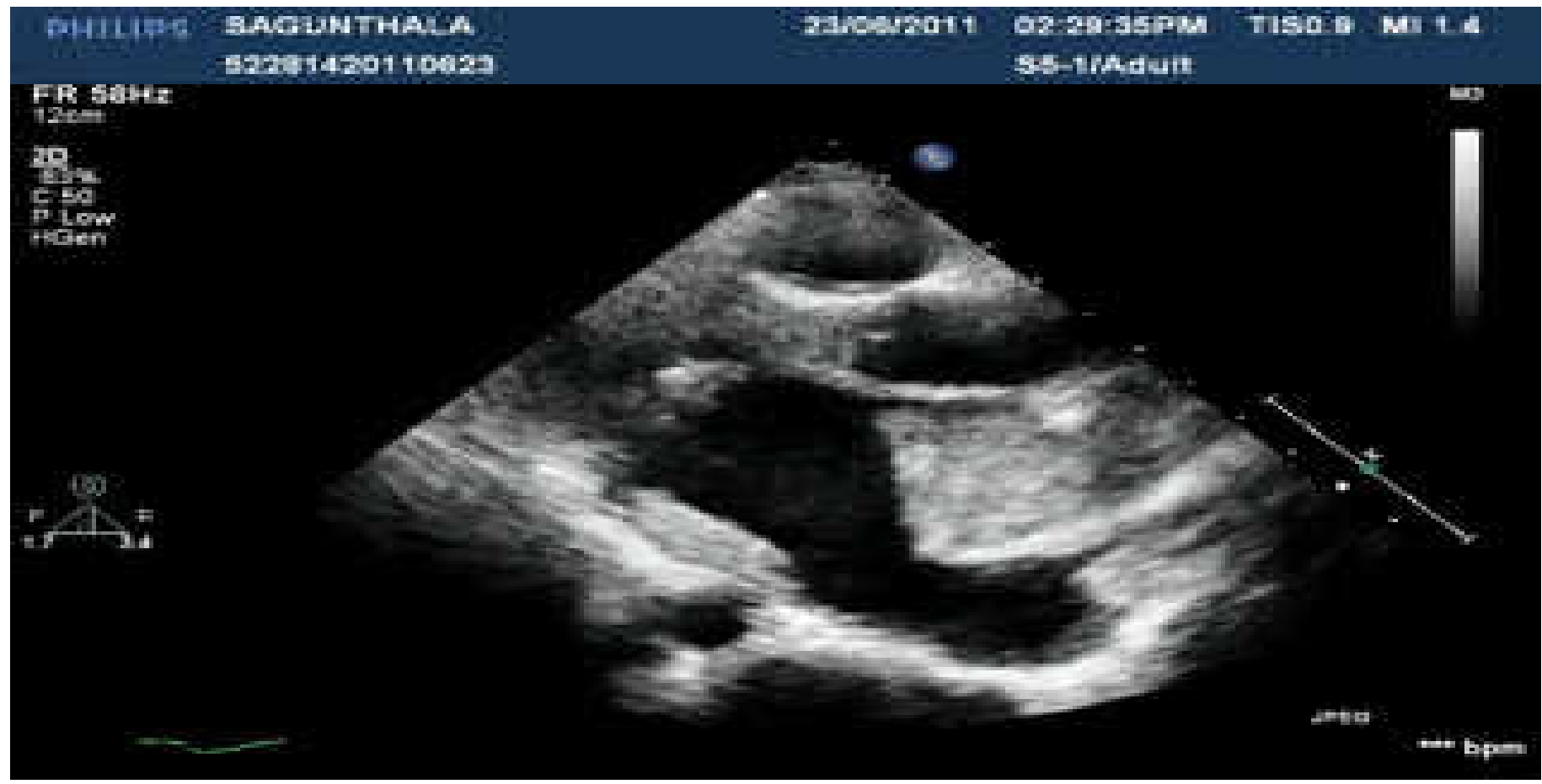

Supplementary: movie clip 1 


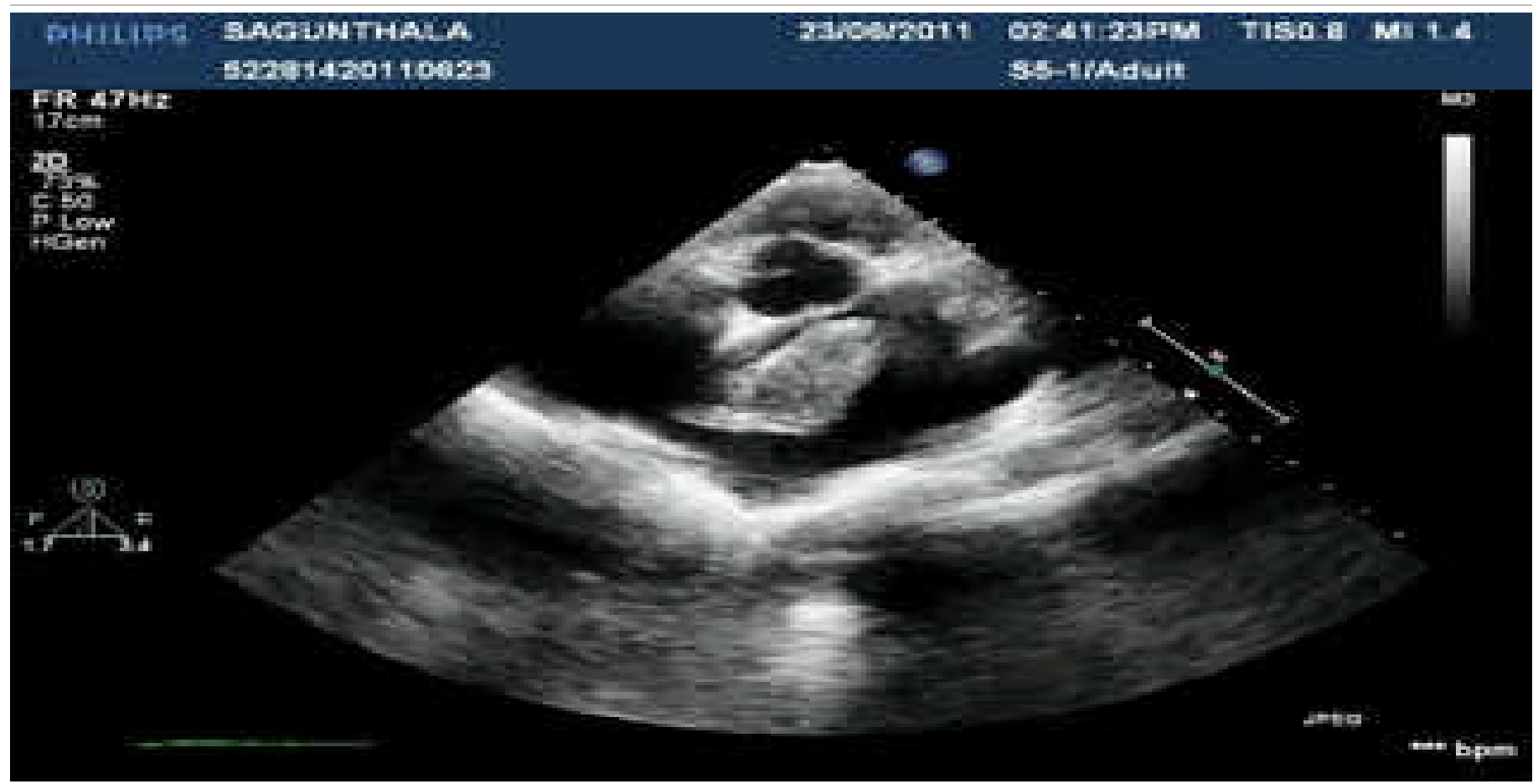

Supplementary: movie clip 2

"Back to Top"

\section{References}

1. Shrestha, N.K., Moreno, F.L., Narciso, F.V., et al. Two-dimensional echocardiographic diagnosis of left-atrial thrombus in rheumatic heart disease. A clinicopathologic study. (1983) Circulation 67(2): 341-347.

Pubmed | Crossref | Others

2. Fazlinezhad, A., Golmohammadzadeh, H., Azari, A., et al. Echocardiographic Predictors of Left Atrial Thrombus in Patients With Severe Rheumatismal Mitral Stenosis. (2014) Razavi International Journal of Medicine 2(1): e15602.

Crossref | Others

3. Ali, S.N., Akram, M., Zareef, A. Comparison of Frequencies of Left Atrial Thrombus in Patients of Severe Mitral Stenosis with and Without Atrial Fibrillation Undergoing Transesophageal Echocardiography for Percutaneous Transv-septal Mitral Commissurotomy. (2015) P J M H S 9(4): 1166-1169.

Others

4. Manjunath, C.N., Srinivasa, K.H., Panneerselvam, A., et al. Incidence and predictors of left atrial thrombus in patients with rheumatic mitral stenosis and sinus rhythm: a transesophageal echocardiographic study. (2011) Echocardiography 28(4): 457-460.

Pubmed | Crossref | Others

5. Nishimura, R.A., Otto, C.M., Benow, R.O., et al. 2014 AHA/ACC guidelines for the management of patients with valvular heart disease: a report of the American College of Cardiology/American Heart Association Task Force on Practice Guidelines. (2014) J Thorac Cardiovasc Surg 148(1): e1-e132.

Pubmed | Crossref | Others

6. Blase A. Carabello. Modern Management of Mitral Stenosis. (2005)

Circulation 112(3): 432-437.

Pubmed | Crossref | Others

Ommega Online Publishers

Journal Title: Journal of Heart and Cardiology

Short title : J Heart Cardiol
Journal ISSN: 2378-6914 (online)

Journal E-mail: cardiology@ommegaonline.com

Website: www.ommegaonline.org 